\title{
RF Sputtered Silicon and Hafnium Nitrides: Properties and Adhesion to 440C Stainless Steel
}

\author{
A. Grill \\ Ben Gurion University of the Negev \\ Beer Sheva, Israel \\ and \\ P. R. Aron \\ Lewis Research Center \\ Cleveland, Ohio
}

Prepared for the

International Conference on Metallurgical Coatings sponsored by the American Vacuum Society

San Diego, California, April 18-22, 1983

\section{NASA}




\author{
RF SPUTTERED SILICON AND HAFNIUM NITRIDES: \\ PROPERTIES AND ADHESION TO 440C STAINLESS STEEL* \\ A. Grill \\ Ben Gurion University of the Negev \\ Beer Sheva, Israel \\ P. R. Aron \\ NASA Lewis Research Center \\ Cleveland, Ohio
}

\begin{abstract}
Silicon nitride and hafnium nitride coatings were deposited by reactive RF sputtering on oxidized and unoxidized 440C stainless steel substrates. Sputtering was done in mixtures of argon and nitrogen gases from pressed powder silicon nitride and from hafnium metal targets. Depositions were at two background pressures, 8 and 20 mtorr, and at two different fractions of nitrogen in argon, 0.25 and 0.60 , for hafnium nitride and at $f=0.25$ for silicon nitride. The coatings and the interface between the coating and substrate were investigated by $X$-ray diffractometry, scanning electron microscopy, energy dispersive $X-r$ ay analysis and Auger electron spectroscopy. A knoop microhardness of $1650 \pm 100 \mathrm{~kg} / \mathrm{mm}^{2}$ was measured for hafnium nitride and $3900 \pm 500 \mathrm{~kg} / \mathrm{mm}^{2}$ for silicon nitride. The friction coefficients between a $440 \mathrm{C}$ rider and the coatings were measured under lubricated conditions. Scratch test results demonstrate that the adhesion of hafnium nitride to both oxidized and unoxidized $440 \mathrm{C}$ is superior to that of silicon nitride. Oxidized $440 \mathrm{C}$ is found to have increased adhesion, to both nitrides, over that of unoxidized $440 \mathrm{C}$.
\end{abstract}

\title{
INTRODUCTION
}

The group IV nitrides are characterized by chemical stability, good dielectric properties and high hardness. As a result, there has been a growing interest in the properties of and synthesis techniques for thin films of these materials. They are finding increasing application in the electronics industry (ref. 1), as decorative coatings (ref. 2), for solar cell applications (ref. 3 ) and as wear reducing coatings for cutting tools (ref. 4). At this laboratory, in pursuit of the tribological properties of promising materials, a study of the characteristics of silicon and hafnium nitrides produced by reactive RF sputtering was begun. This technique offers the advantage of a relatively low substrate temperature. The dependence of the composition and rate of deposition on the concentration of nitrogen in the sputtering gas and on the sputtering pressure has been reported (refs. 5 and 6). It was found that the adherence of silicon nitride to 304 stainless steel improves with decreasing sputtering pressure. Since the adherence 
of the coatings is an important factor for practical applications, the study, focused on two materials, silicon nitride and hafnium nitride, is continued. It's goal is to gain a better understanding of the relationship between the deposition conditions, the structure and composition of the coatings and the interface, and their adherence to an important bearing material, hardened $440 \mathrm{C}$ stainless steel. It has been shown (ref. 7 ) that the adhesion of some hard coatings to this material is improved if the surface, of the substrate, is oxidized. Therefore, for the present study, both oxidized and unoxidized substrates are used.

\section{SAMPLE PREPARATION}

The coatings were deposited in the diode type RF sputtering system described in Ref. 6. The silicon nitride was deposited from a commercially obtained high purity pressed powder silicon nitride target at two total pressures, 8 and 20 mtorr in a gas mixture 25 percent (molecular nitrogen in argon $(f=0.25)$. The hafnium nitride was deposited from a VP hafnium metal target at the same two total pressures with $f=0.25$ and 0.60 . A typical deposition rate was $190 \AA / \mathrm{min}$. The substrates were disks of $440 \mathrm{C}$ stainless steel, $1.0 \mathrm{~cm}$ in diameter and $1.6 \mathrm{~mm}$ thick, hardened to 55 Rockwell $\mathrm{C}$ by heating to $870^{\circ} \mathrm{C}$ for 15 min followed by an 0 il quench. After hardening all substrates were polished with $1 \mu \mathrm{m}$ diamond paste and ultrasonically cleaned in Alconox, acetone and 190 proof ethyl alcohol. The substrates to be oxidized were heated, in air, at $350^{\circ} \mathrm{C}$ for 17 hours which resulted in a hardness 50 Rockwell C. The same cleaning procedure was followed after oxiding.

\section{RESULTS AND DISCUSSION}

Morphology

Figure 1 is an SEM micrograph of a silicon nitride coating which shows a morphology typical of both materials as deposited on unoxidized substrates. These coatings are smooth and reproduce the geometric features (scratches, etc.) of the substrates. Coating deposited on oxidized substrates are rougher, reflecting the character of the substrates. The coating's habit can be seen at the edge and appears to be fine grained. In contrast, the silicon nitride, deposited at 20 mtorr on the oxidized 440C, exhibits a much coarser grain columnar growth pattern (fig. 2). The formation of this structure is expected to be favored by rough substrates and low substrate temperatures (ref. 8). At low temperatures the arriving atoms are incorporated into the coating close to their points of impact. This allows shadowing to play an important role in the crystal growth. Peaks will "see" a higher flux than the valleys if a significant transverse component of velocity is present. The failure of the hafnium nitride coatings to develop the columnar structure may be related to the self-bias of the hafnium target $(2.2 \mathrm{kV})$ which is significantly higher than the self-bias of the silicon nitride target $(1.4 \mathrm{kV}$ ). It has been shown (ref.9) that this will lead to higher energy sputtered atoms and incomplete thermalization. This implies that the hafnium atoms are not only more mobile but, on arrival at the substrate, have smaller average transverse component of velocity. Both conditions are expected to lead to a reduced tendancy to develop a columnar structure. 
The X-ray diffractometer data for the silicon nitride coatings showed no evidence of crystalinity. The hafnium nitride films however did exhibit broad peaks consistant with crystalites with a characteristic linear dimension of at least $\sim 50 \AA$. The diffraction pattern in all cases suggested mixed phases of $\mathrm{HfN}$ and $\mathrm{Hf}_{4} \mathrm{~N}_{3}$. The coatings deposited with $f=0.60$ were predominantly $\mathrm{HFN}$ while those deposited with $f=0.60$ were predominantly $\mathrm{HfN}$ while those deposited with $\mathrm{f}=0.25$ were predominantly $\mathrm{Hf}_{4} \mathrm{~N}_{3}$.

\section{Auger Electron Spectroscopy}

The composition of the coatings and the variation of composition through the interface between the coating and substrate was studied by Auger electron spectroscopy (AES) as described in Ref. 6. Spectra were obtained while the films were being ion beam milled with $3 \mathrm{kV}$ argon ions. The ion beam was rastered over an area $3 \mathrm{~mm}$ by $8 \mathrm{~mm}$. A sputter rate of $13 \AA / \mathrm{min}$ was typical under these conditions. Figure 3 is a spectrum (50 to $1000 \mathrm{kV}$ ) which, after ion milling to remove the contaminated surface layer, is typical of the silicon nitride coatings studied. It has features corresponding to the LMM lines of silicon and argon and KLL lines of carbon, oxygen and nitrogen. The ion milling has the effect of increasing the energy of the major silicon line from $85 \mathrm{eV}$ to $92 \mathrm{eV}$. This behavior has been observed previously (ref. 10) and has been interpreted as an electron and/or ion beam induced decomposition of the nitride. It was found, in this work, that, from the point of view of coating purity and stoichiometry, the lower (8 mtorr) deposition pressure is associated with the better films. They have a nitrogen to silicon peak to peak ratio in agreement with a published (ref. 11) value for $\mathrm{Si}_{3} \mathrm{~N}_{4}$. Their carbon contamination is approximately $1 / 2$ of that of the 20 mtorr samples and the oxygen contamination is lower by about a factor of 3 . Depth profiles, fig. 4, typically exhibit a narrow ( $\sim 50 \AA)$ contaminated surface layer followed by the coating ( 1000 $\AA)$. There next appears a wide interface which contains oxides and a mixed phase zone followed by the substrate. It should be recognized that the apparent width of the interface is greater than the true width. This is primarily due to the nonideal way in which the ion beam interacts with the sample (ref. 12). The most important resolution limiting effect in this work is undoubtedly a geometric one. The SEM confirms that the ion beam does not mill the surface uniformly. Under these conditions the AES signal is a weighted average of spectra from a wide range of depths. Even under the limitation described above consistent behavior was observed. The interface widths of the coatings on the unoxidized substrates are $300 \AA$ for the 20 mtorr samples and $150 \AA$ for the 8 mtorr coatings. The interfaces of the coatings on the oxidized substrates are all $600 \AA$ wide. The interface "width" is defined here as the distance from the point where the silicon or hafnium amplitude is 0.8 of its bulk value to the point where the iron amplitude is 0.8 of its bulk value. The maximum value of the oxygen peak in this region is approximately the same in both the oxidized and unoxidized cases. The interfaces in all cases are rich, relative to nominal bulk 400C values, in chrome.

The typical spectrum of hafnium nitride exhibits the same features except that silicon is replaced by hafnium. However, in contrast to silicon nitride, no correlation was observed between the oxygen and carbon impurity levels and the sputtering conditions. The depth profiles show the interface region to have the same oxide and interface widths as seen for silicon nitride. 


\section{Friction Coefficients}

The apparatus, described in Fig. 2 of Ref. 13, was used to measure the friction coefficients. The rider was a $440 \mathrm{C}$ hemisphere, $7 \mathrm{~mm}$ in diameter, hardened to 47 Rockwell $C$ then polished. The fricton was measured at a normal load of 100 grams. The rider was lubricated with a light mineral oil, which had a viscosity of 20 centistokes. The friction is characterized by two coefficients, the minimum value ( $\mu \mathrm{min}$ ) and a maximum value $\left(\mu_{\max }\right)$. No systematic dependence of these parameters on the sputtering conditions was observed for either silicon nitride or hafnium nitride. The coefficients, $\mu$ min and $\mu$ max, for the uncoated and unoxidized substrates were found to be 0.19 and 0.21 respectively, and 0.19 and 0.42 for the uncoated and oxidized substrates. In the case of the coated samples both materials show no difference between the oxidized and unoxdized substrates. For silicon nitride umin and $\mu$ max, are 0.33 and 0.52 . For hafnium nitride the same coefficients are 0.42 and 0.73 .

\section{Microhardness}

The microhardness was measured with a knoop indenter at loads of 10 and $25 \mathrm{~g}$. The apparent microhardness of the coatings, as deposited on oxidized substrates, is higher than that measured on the same coatings deposited on unoxidized substrates which indicates the superiority of their adhesion to the oxided surfaces. For example, a microhardness of $2265 \mathrm{~kg} / \mathrm{mm}^{2}$ at $10 \mathrm{~g}$ was measured for a $1.5 \mu \mathrm{m}$ thick silicon nitride film deposited at $8 \mathrm{mtorr}$ on an oxidized substrate. In contrast, only $1131 \mathrm{~kg} / \mathrm{mm}^{2}$ at $10 \mathrm{~g}$ was measured for the same material deposited on an unoxidized substrate. The microhardness measured at $10 \mathrm{~g}$ was always larger than that measured at $25 \mathrm{~g}$ which indicates that the films are not sufficiently thick $(T)$, with respect to the depth of penetration of the indentor (D), to exhibit buik behavior. In an attempt to observe the bulk hardness some thicker silicon nitride films were prepared. A $2.3 \mu \mathrm{m}$ thick silicon nitride coating deposited at 8 mtorr on an oxidized substrate exhibited the highest hardness, $3900 \pm 500 \mathrm{~kg} / \mathrm{mm}^{2}$ at a 10 $\mathrm{g}$, in this case, $\mathrm{d} / \mathrm{t}$ is less than 0.1 . It has been shown (ref. 14) that this is a condition under which the true bulk value would be observed and is, within experimental error, in agreement with a previously reported (ref. 15) value of $3260 \mathrm{~kg} / \mathrm{mm}^{2}$. The hardest hafnium nitride coatings were deposited at 8 mtorr with $f=0.25$. A $1.2 \mathrm{~mm}$ thick coating deposited on an oxidized substrate exhibited a hardness of $1650 \pm 100 \mathrm{~kg} / \mathrm{mm}^{2}$ at $10 \mathrm{~g}$. Although this is in agreement with published values (ref. 16) it must be considered to be only a lower limit since $D / T$ is, in this case, 0.25 .

Scratch Tests

The relative adhesion of the films to the substrates was studied by means of a scratch test. The scratches were produced by sliding a loaded spherical diamond indentor with a radius of $86 \mu \mathrm{m}$, once over the surface. The critical load was defined as that load with which the coating appeared, in the SEM, to crack. SEM examination also revealed that, at the critical load, Fig. 5, the silicon nitride exhibits evidence for brittle failure and poor interfacial adhesion while at loads above critical the coating is removed completely from the track. Hafnium nitride coatings subjected to their critical loads, Fig. 6, also shows some cracking and flaking at the edges. However, in the track, the coating appears to fail in a ductile manner and 
remain bonded to the substrate. The data in Figs. 5 and 6 demonstrate that adhesion of these materials to $440 \mathrm{C}$ is improved by oxidizing the substrate. Adhesion is also improved by depositing them at the lower pressure ( $8 \mathrm{mtorr}$ ). The best adhesion, in the case of hafnium nitride, is associated with the films deposited with $f=0.60$. These films were found to be most nearly stoichometric HfN.

Although it is difficult to directly compare the two materials with respect to their behavior in this test, it does appear that the oxide has a larger effect on the adhesion in the case of silicon nitride than it has on the adhesion of the hafnium nitride. This behavior is made plausible if the thermal contribution to the interfacial stresses is examined. Since the thermal expansion coefficients of both silicon nitride $\left(\sim 2 \times 10^{-6} \mathrm{C}^{-1}\right)$, and hafnium nitride $\left(5.4 \times 10^{-6} \mathrm{C}^{-1}\right.$, ref. 18) are smaller than that of $440 C\left(5.6 \times 10^{-6} c^{-1}\right.$, ref. 19) shear stresses will develop at the interface as the sample cools to room temperature after deposition. Assuming similar thermal histories, their relative thermal expansion coefficients and hardnesses suggest that silicon nitride will show a higher interface stress than hafnium nitride.

\section{CONCLUSIONS}

(1) The coatings have a surface morphology which are smooth and reproduce the geometry of the substrate with the exception of the silicon nitride deposited, at 20 mtorr, on oxidized substrates which exhibits a columar structure.

(2) The silicon nitride coatings were found to be amorphous whereas the hafnium nitride films showed evidence of crystalinity with a grain size of at least $\sim 50 \AA$.

(3) X-ray diffractometry suggests that the hafnium nitride is a mixture of phases. The coatings deposited with $f=0.6$ were predominately HfN while those with $f=0.25$ showed the $X$-ray diffraction lines, corresponding to $\mathrm{Hf}_{4} \mathrm{~N}_{3}$, to be more intense. This is consistent with the AES results which showed that the films deposited at the higher value of $f$ were richer in nitrogen.

(4) Silicon nitride showed significantly higher impurity levels (oxygen and carbon) than the hafnium nitride. This may be the result of the outgasing from the pressed powder target.

(5) The friction coefficient, relative to hardened $440 \mathrm{C}$ steel, ranged from 0.33 to 0.56 for silicon nitride and from 0.42 to 0.73 for hafnium nitride.

(6) Microhardness of $1650 \pm 100 \mathrm{~kg} / \mathrm{mm}^{2}$ and $3900 \pm 500 \mathrm{~kg} / \mathrm{mm}^{2}$ were measured for the best hafnium nitride and silicon nitride respectively. These values are in agreement with the bulk values quoted in the literature.

(7) Adhesion of both silicon nitride and hafnium nitride to hardened $440 \mathrm{C}$ steel, as measured by the scratch test, is improved by a reduced sputtering pressure and by preoxidizing the substrates. The hafnium nitride exhibits ductile failure and remains in the track at loads greater than twice the critical load. This is in contrast to silicon nitride, which is removed completely from the track at any load significantly above the critical. 


\section{REFERENCES}

1. M. Sekimoto, H. Yoshihara, T. Ohkubo, and T. Saitoh, Jpn. J. Appl. Phys., 20, L669 (1981).

2. T. Tomita, I. Kasai, and T. Koshiki, Japanese Patent A7630525 (1971).

3. R. Henzel and R. Schorner, J. Appl. Phys., 52, 3076-3079 (1981).

4. M. Kodama, A. H. Shabaik, and R. F. Bunshah, Thin Solid Films, 54, 353-357 (1978).

5. A. Grill, and P. R. Aron, Thin Solid Films, 96, 25-30 (1982).

6. P. R. Aron and A. Grill, Thin Solid Films, 96, 87-91 (1982).

7. W. A. Brainard, "The Friction and Wear Properties of Sputtered Hard Refractory Compounds," NASA TM-78895, Aug. 1978.

8. J. A. Thornton and D. W. Hoffman, in 22nd Annual Technical Conference proceeding of the Society of Vacuum Coaters, (Society of Vacuum Coaters, New Jersey, 1979).

9. C. T. Wu, R. T. Kampwirth, and J. W. Hafstrom, J. Vac. Sci. Technol., 14, 134-137 (1977).

10. J. F. Delord, A. G. Schrott, and S. C. Fain, Jr., J. Vac. Sci. Technol., $\underline{17}, 517-520$ (1980).

11. G. E. McGuire, Auger Electron Spectroscopy Reference Manual, (Plenum Press New York, 1979).

12. G. Carter, A. Gras-Marti, and M. J. Nobes, Radiat. Eff., 62, 119-152 (1982).

13. K. Miyoshi, and D. H. Buckley, "Friction and Surface Chemistry of Some Ferrous-Base Metallic Glasses," NASA TP-1991, Mar. 1982.

14. H. C. Angus, Trans. Inst. Met. Finish., 39, 20-28 (1962).

15. "Engineering Property Data on Selected Ceramics, Vol. I, Nitrides," MCIC-HB-07-Vol-1, Mar. 1976, p. 47.

16. "Engineering Property Data on Selected Ceramics, Vol. I, Nitrides," MCIC-HB-07-Vol-1, Mar. 1976, p. 72.

17. P. T. B. Shaffer, Materials Index, (Plenum Press, New York, 1964), p. 284 .

18. "Engineering Property Data on Selected Ceramics, Vol. I, Nitrides," MCIC-HB-07-Vol-1, Mar. 1976, p. 71.

19. Mater. Eng., 96, (6), C39 (1982). 


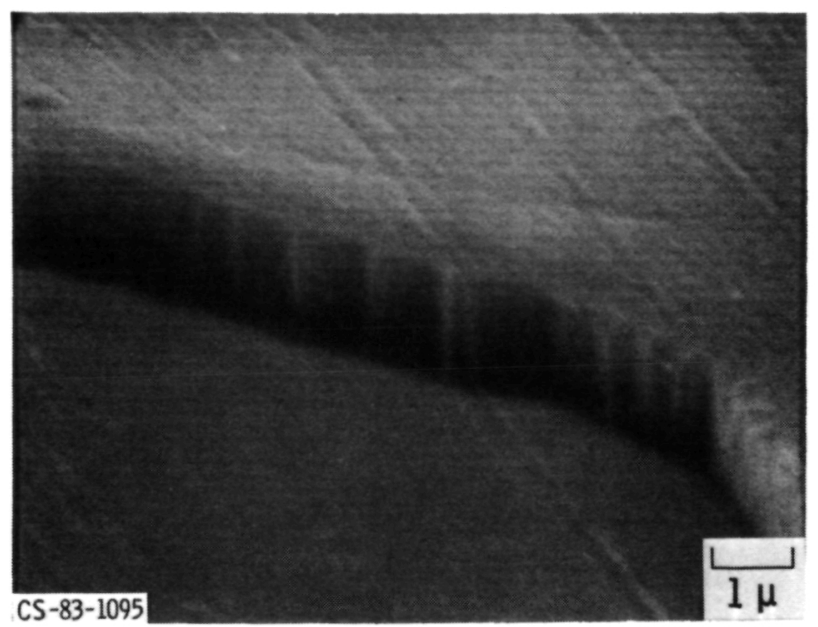

Figure l. - SEM micrograph of a silicon nitride coating deposited at $8 \mathrm{~m}$ torr on $\triangle 40 \mathrm{C}$ steel.

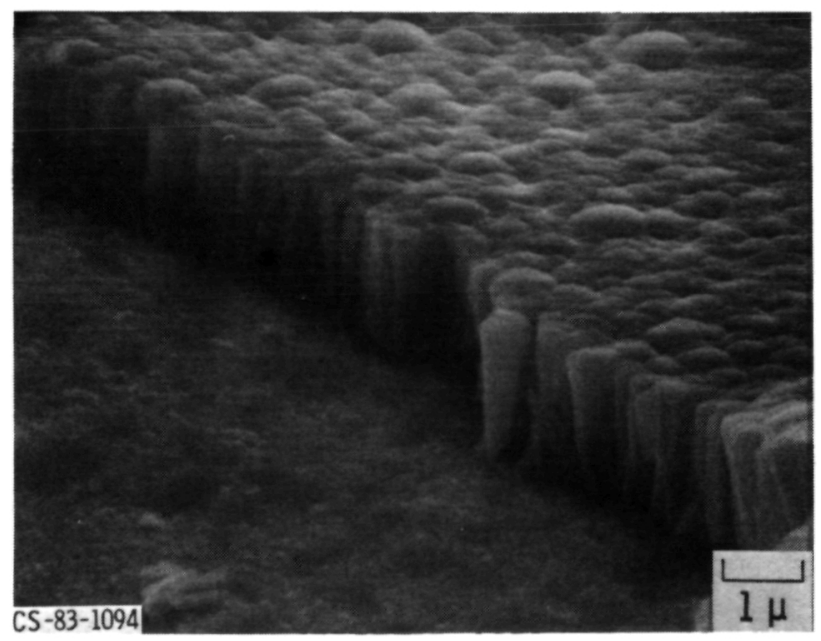

Figure 2. - SEM micrograph of a silicon nitride coating deposited at $20 \mathrm{~m}$ torr on oxidized $440 \mathrm{C}$ steel. 


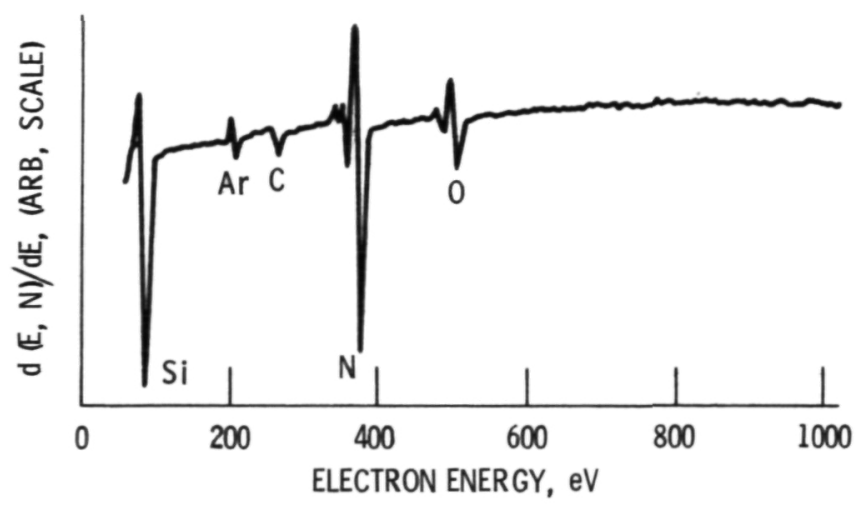

Figure 3. - AES spectrum of a silicon nitride coating deposited at 8 mtorr after ion milling.

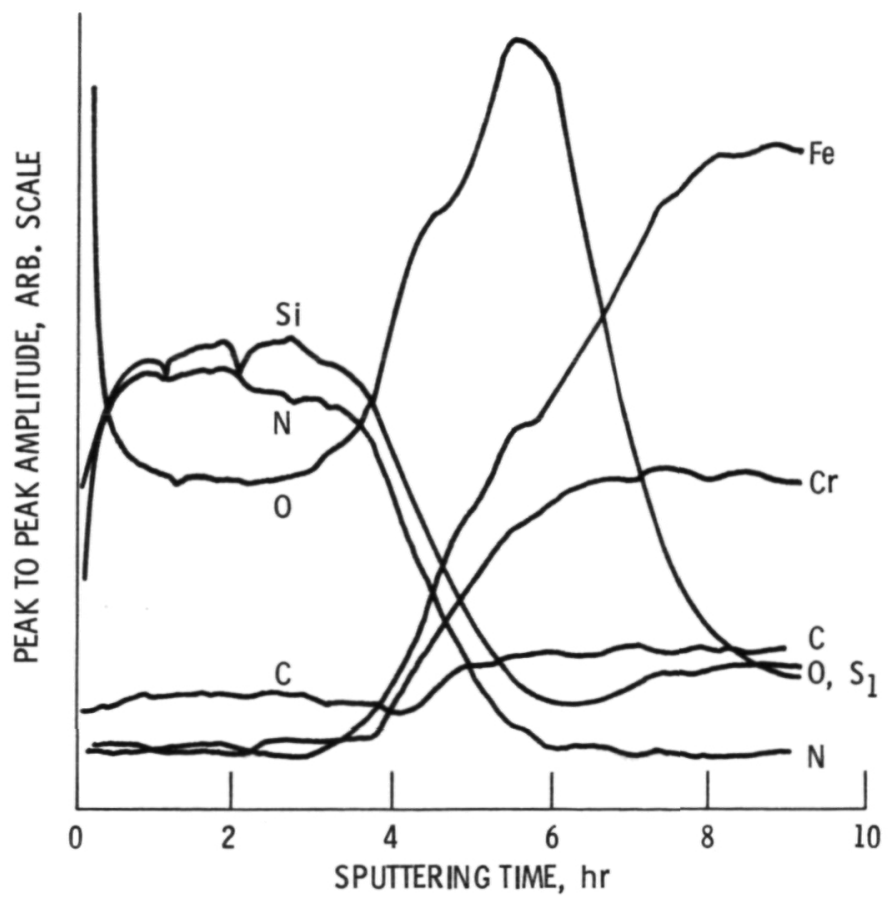

Figure 4. - AES depth profile of a silicon nitride coating deposited at 20 mtorr on oxidized $440 \mathrm{C}$ steel. 


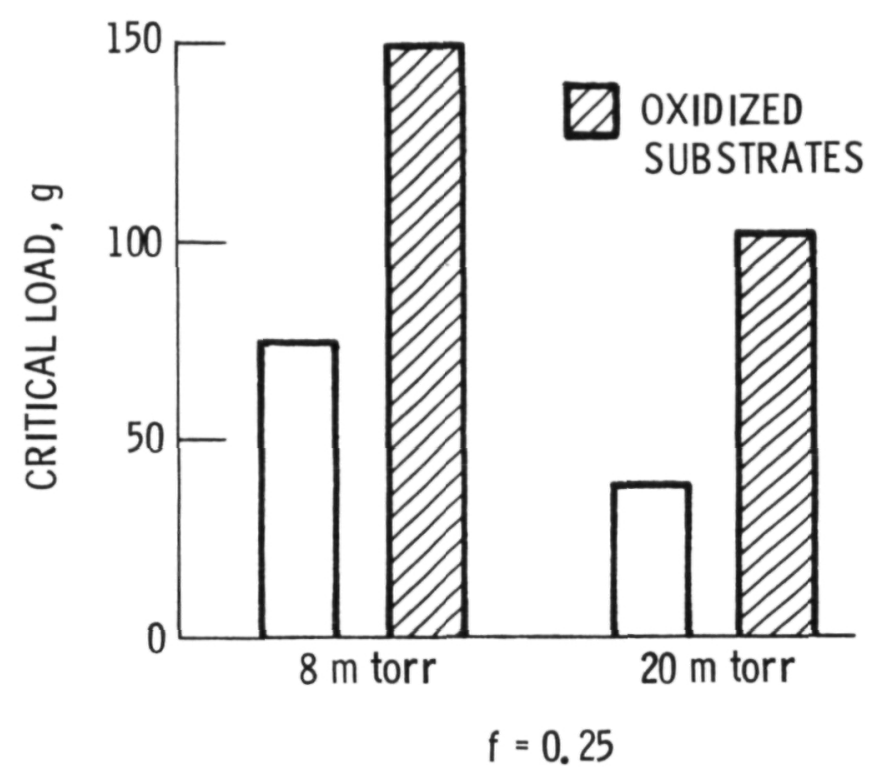

Figure 5. - Critical loads vs sputter conditions for silicon nitride on $440 \mathrm{C}$ steel.

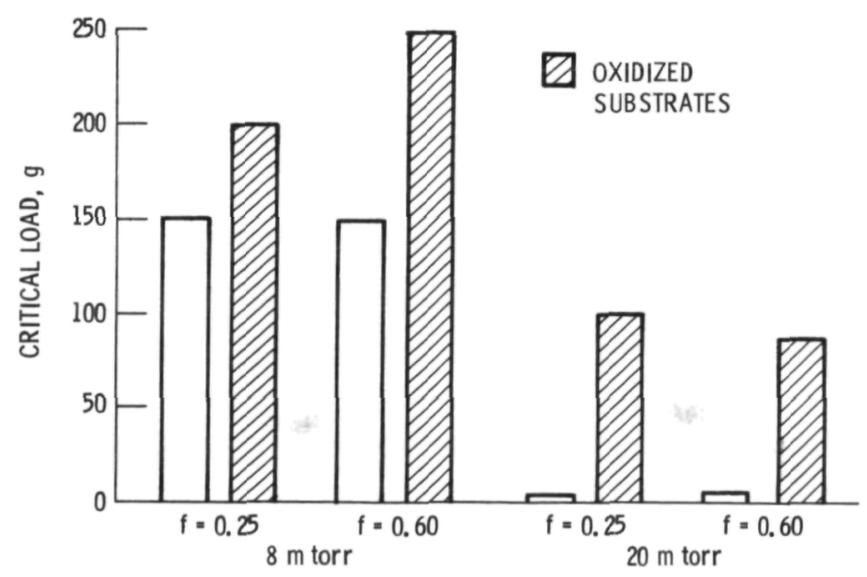

Figure 6. - Critical loads vs sputter conditions for hafnium nitride on $400 \mathrm{C}$ steel. 


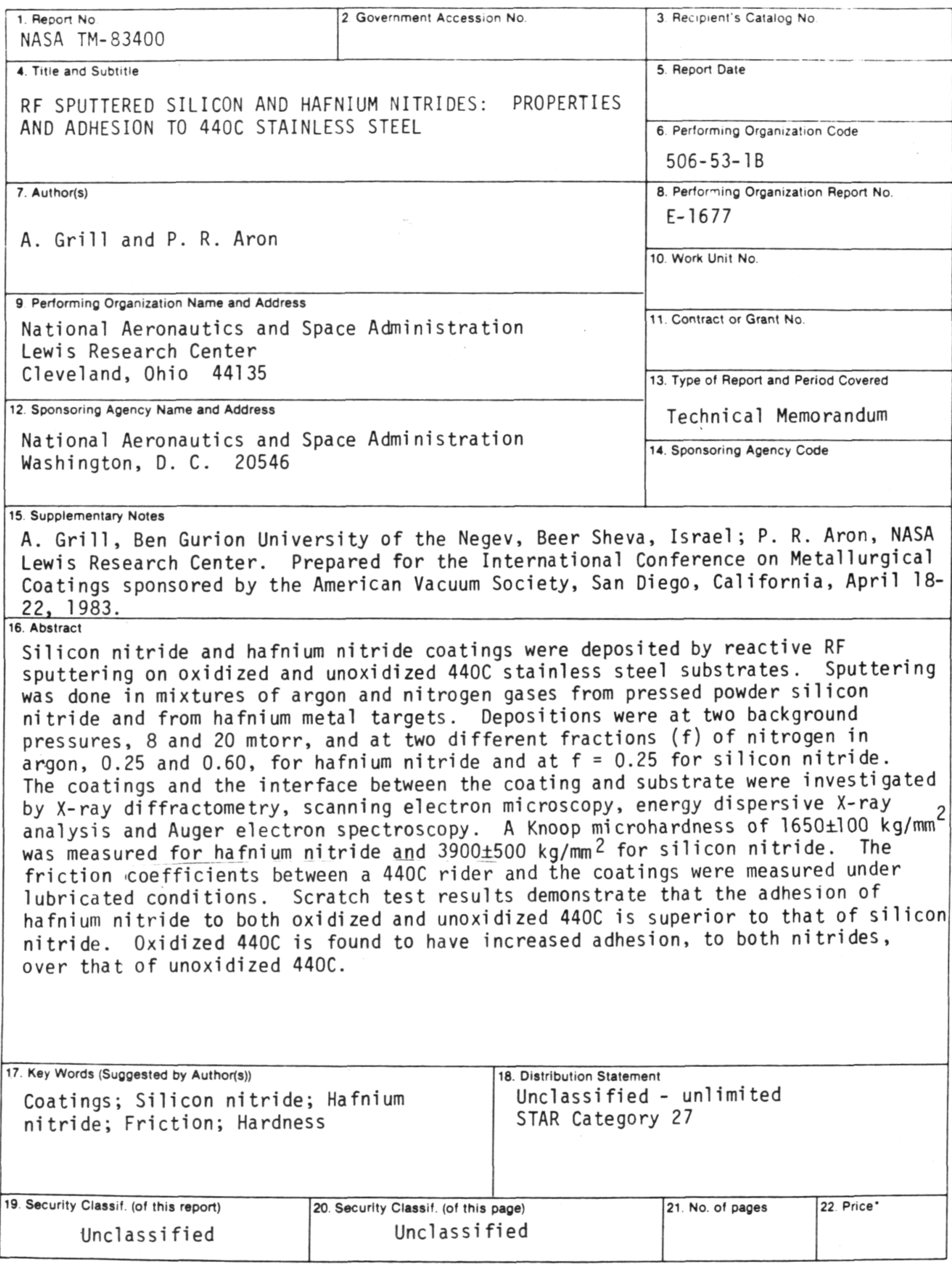

* For sale by the National Technical Information Service. Springfield. Virginia 22161 
National Aeronautics and Space Administration

Washington, D.C.

20546

Official Business

Penalty for Private Use, $\mathbf{\$ 3 0 0}$

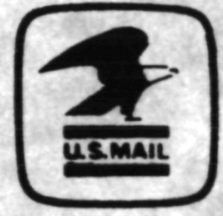

Postage and Fees Paid National Aeronautics and Space Administration NASA-451 